\title{
A Study on Functional Equivalence in Translation of Lyric Prose - A Case of Autumn in Peiping by Zhang Peiji
}

\author{
Rui Zhou \\ College of Foreign Studies, Jinan University, Guangzhou, China
}

\begin{abstract}
The Functional Equivalence Theory put forward by Eugene Nida, an American translation theorist, notes that translation is a process of using the closest and most natural equivalent in the target language to reproduce the information of the source language. It emphasizes the equivalence of information content and form, and prose translation aims to convey information and reproduce the style of the source text. Therefore, the Functional Equivalence Theory has great application space in the text analysis of prose translation. In this paper, the author discusses how to apply the theory of Functional Equivalence to the translating of modern Chinese lyric prose into English. Taking Autumn in Peiping translated by Zhang Peiji as a case study, the author of this paper explores how the translator achieved equivalence in lexical, syntactical and stylistic aspects on the ground of citing typical examples. The method of qualitative research is used in this paper. In the framework of the Functional Equivalence Theory, the author tries to analyze and evaluate how word choice, sentence structure and style function in conveying the meaning of the source text. It is found that the theory of Functional Equivalence is of guidance in analyzing the translation effect of Autumn in Peiping. Lexically, equivalence is realized through correspondence, non-correspondence and zero in semantic translation. Syntactically, the translator used different sentence structures and cohesive devices to convey the intended meaning. Stylistically, some workable strategies are adopted to deal with translation difficulties in expressive function and aesthetic appeal.
\end{abstract}

Index Terms-functional equivalence, Autumn in Peiping, lyric prose

\section{INTRODUCTION}

Autumn in Peiping is a Chinese prose written by Yu Dafu, a famous modern Chinese novelist, proser, and poet, in August 1934. It is a text of more than 1,500 words to present readers a "clean, serene and melancholy" autumn. With a total of fourteen paragraphs, it can be divided into three parts. At its beginning and end, Yu Dafu compared the autumn in the North with that in the South to show that he liked autumn in Beijing better. The middle part describes the colorful autumn scenery of the former capital. Writing techniques of narration are woven with those of description and discussion. Parallel structures are employed to depict the natural scenery in autumn. Images of locust tree, cicada, rain and fruit tree are presented here. Happy morning, fallen petal traces, chirping cicadas, urban idlers, autumn fruits unfold before readers. This prose contains deep love for the one-time capital and the motherland, and the author attempted to arouse people's pursuit of beauty and love for the motherland. Its language is precise and well-organized, with the expressive force of dynamic and static combination. It reflects the cultural characteristics of North China, and its language is of great aesthetic appealing. Yu carefully selects unique images with autumn characteristics and uses various rhetorical devices to describe them. The blending of scenes and emotion is the mainly adopted writing technique and it is a good combination of life attitude and description of scenes.

Professor Zhang Peiji, a famous translator and distinguished scholar in China, has contributed quite a few articles to the column of "Self-study of Translation, Chinese-English Translation Practice" of Chinese Translators Journal. The consensus of opinion for a long time has accepted those articles as supreme in the circle of translation. Translators are in their unanimous praise of them, for they are natural and fluent and they are of highly literary value, fully reflecting the philosophy of the translator in view of translation. Many readers and translation devotees have benefited a lot from them. Later, his translations were collected and published in Selected Modern Chinese Essay. They provide much guidance for Chinese scholars who are interested in studying translation theories and techniques. The English version of Autumn in Peiping, taken from Selected Modern Chinese Essay, is translated by Zhang Peiji. It is a masterpiece which is acknowledged to be such by all the best critics in the world of the translation of Chinese modern lyric prose. In this paper, the author tries to make an analysis of the translation of Autumn in Peiping translated by Zhang Peiji in the framework of the Functional Equivalence Theory put forward by Eugene Nida with the purpose to provide some practical translation strategies for the English translation of modern lyric prose works in China through an in-depth discussion of how equivalence is achieved in the translated Autumn in Peiping in lexical, syntactical and stylistic aspects in hope of promoting the intercultural communication between China and the English world. 


\section{LITERATURE REVIEW}

\section{A. Functional Equivalence Theory and Translation}

The Functional Equivalence Theory (FET) is developed from the Dynamic Equivalence Theory. Since the 1950s, Nida began to use the theory of Dynamic Equivalence to guide the practical work of Bible translation (Tan Zaixi, 1999, p.XIX). In 1964, Nida emphasized the concept of "dynamic equivalence" in his book Toward a Science of Translating. The influence of Nida's theory slowly grew. In Germany, Wolfram Wilss published The Science of Translation: Problems and Methods (1982).The theory of Translation Science dominated the teaching of translation at the University of Saarkand, a training base for translators in Germany (Guo Jianzhong, 1999, p. 69). In the United States, Nida's translation theory was used in some textbooks and more and more people showed interest in it.

However, some scholars showed different opinions to the Functional Equivalence Theory. Susan Bassnett-McGuire pointed out in Translation Studies (1980) that Nida's equivalence theory is too lax and with the drawbacks of free translation (ibid, p.78). Peter Newmark believed that topics such as translation equivalence and translation unit should be abandoned because they are either too theoretical or too random (Tu Guoyuan and Liao Jing, 2001, p. 42).

In 1986, Nida formally proposed the concept of Functional Equivalence in From One Language to Another: Functional Equivalence in Bible Translation. It is controversial whether Functional Equivalence theory is only applicable to Bible translation. W. Wilss (1982) pointed out that translation equivalence could not be included in general translation theories, but could only serve as a part of specific translation theories, which was targeted at specific texts, or even only applied to single text (ibid, p. 42). In An interview with Dr. Eugene Nida, published in the second issue of Journal of Foreign Languages in 1998, Nida made explanation for this question. He replied that his principles of translation had been formed long before the Bible translation (1998, p. 2). In other words, Functional equivalence is not only based on biblical translation. It can also apply to the translation of other genres. He also pointed out that biblical translation and non-serious literary translation are generally similar in terms of translation purposes and translation methods, both aiming at delivering the basic meaning of the original text and serving the readers (Ni Wanhui, Yang Yin, 2004, p. 34). Therefore, Functional Equivalence theory is applicable to prose translation.

\section{B. Prose Translation and Functional Equivalence}

Prose translation is an important part of literary translation. In the past ten years, 577 papers have been published on the topic of "prose translation". Of them, Zhang Peiji's translation studies and translation aesthetics are the two main research directions. In On rhythm in prose translation, Yu Dong and Liu Shicong (2014) studied the composition and aesthetic function of rhythm in English and Chinese prose, and the reappearance of rhythm in English and Chinese prose in translation. They found that "English and Chinese prose rhythms have different aesthetic pursuit ways" and "to strengthen the text emotion, promote the theme of thinking" (ibid, p. 96) are the goals of English and Chinese prose rhythm. In 2015, Zhou Lingshun published Beauty and truth in prose translation on Chinese Translators Journal. She took the Chinese translation of My Life's Sentences as the research object and pointed out that the key to improving the quality of prose translation is to lay a solid foundation of bilingual skills (Zhou Lingshun, 2015, p. 117).

There is small number of studies on lyric prose translation, whose research directions include prose poetry, prose English translation, translation aesthetics, stylistics, translation quality assessment, etc. in recent ten years. Lv Gui (2010) evaluated the quality of the English translation of the lyric prose Autumn in Peiping based on the translation quality assessment model of systemic functional linguistics, and found that the conceptual and interpersonal meanings of the study text were intermixed, and the evaluators' judgments on the deviation cases and the quality of the translation were subjective. Li Jiaojiao (2013) explored the aesthetic elements in the lyric prose of modern prose masters and their most widely accepted English translation versions from the perspective of formal system and non-formal system.

The Functional Equivalence theory has a certain guiding significance in literary translation and prose translation. Zhang Juan (2011), under guidance of the theory of functional equivalence, took Selected Modern Chinese Essays rendered by Zhang Peiji as the research object, and discoursed on the retention, loss and change of idioms in prose translation when they are translated from Chinese to English. Wang Linhai and Shi Yanting (2014) took the translation practice of Modern Saudi Arabian Literature Narrative Art as an example to discuss the guiding role of Functional Equivalence theory in the processing of linguistic forms and cultural factors in literary translation. They found that the application of functional equivalence theory, combined with translation strategies such as literal translation, augmented translation and transliteration, is conducive to improving the quality of literary translation.

Previous studies have shown that literary translation and prose translation have certain research value, and the Functional Equivalence theory has a certain guiding significance for translation analysis. Lyric proses of various times in China are important texts to understand Chinese culture and its historical development, and the study of its translation is worthy of note. The Functional Equivalence theory provides a feasible framework for the study of this kind of text. Therefore, under the guidance of the theory of Functional Equivalence, this paper is to study the translation methods and techniques adopted by Zhang Peiji in Autumn in Peiping. The author will summarize Zhang's translation techniques in the lexical, syntactic and stylistic aspects. Though she is a beginner in the field of translation study, she wishes to help readers to have a better understanding of the beauty, charm and translation style of Zhang Peiji in translating the modern Chinese prose. 


\section{EQuivalence Achieved in the Translation of Autumn IN PEIPING}

Three aspects of the Functional Equivalence Theory are: lexical equivalence, syntactic equivalence and stylistic equivalence. Lexical equivalence is the basic embodiment of content equivalence. Semantic correspondence, semantic non-correspondence, and semantic zero are related to the referential meaning and the associative meaning discussed in the book From One Language to Another (1986). Syntactic equivalence reflects three levels of the process of analyzing symbolic meaning, in terms of the subject, predicate and sentential structure. Stylistic equivalence is concerned with whether the translation can exhibit the lyric prose features of the source text. Whether the expressive function and aesthetic appeal of lyric prose are maximized in a translation is the ultimate test of equivalence of content and form between the source text (ST) and the target text(TT).

\section{A. Lexical Equivalence}

According to Chen Hongwei and Li Yazhou (2010, p. 32), there are three types of Chinese-English word meaning relationships, namely, semantic correspondence, semantic non-correspondence, and semantic zero. These three categories are both related to the referential meaning and the implied meaning of words. Referential meaning refers to the "exact and literal meaning of a word"(Lu Guoqiang, 1999, p. 117). As shown in Oxford Concise Companion to the English Language, implied meaning refers to the emotional and associative meanings contained in a word.

\section{Semantic Correspondence}

Although different regions have different cultural backgrounds, there are some commonalities between languages, and the meanings of some words are equivalent, due to the similarities between the ecological environment on earth and human cognition of the objective world. Semantic correspondence can be discussed from two aspects. Some Chinese words have only referential meaning without specific reference context, and the translator chooses equivalent words in English to translate them. For example, Zhang Peiji (2007, p. 158) employed "autumn", "air" and "sky" to translate the terms “秋天”, “空气”and“天”in the source text.

However, some words have both referential meaning and implication meaning. In such cases, a translator tends to employ the approach of free translation on the premise of understanding the original text to achieve lexical equivalence. Here is an example:

(1) ST: 一个人夹在苏州上海杭州, 或厦门香港广州的市民中间, 浑浑沌沌地过去...(ibid, p. 158)

TT: While muddling along all by myself among the urban dwellers of Suzhou, Shanghai, Xiamen, Hongkong or Guangzhou... (ibid, p. 162)

The expression “浑浑沌沌” in Chinese refers to a state of confusion. In the source text, the author is describing how he felt about autumn in the south of China, so as to point up his yearning for autumn in his hometown. Instead of choosing haze or befuddled as a word that can describe befuddlement for translation, the translator discovers the author's potential true purpose in using the word and chooses "muddle along" as the translation version. The phrase Muddle along is defined as to continue doing something without any clear plan or purpose in Oxford Advanced Learner's English-Chinese Dictionary (Hornby, 2018). The translator understands that the author has used the word “浑 浑沌沌” not only to describe his aimless wandering among the crowd, but also the author's own idle life in the south. In terms of word selection, the translator accurately grasps the referential and implicit meanings of the words adopted by the author, and the translation realizes the information and expression functions of the words.

\section{Semantic Non-Correspondence}

In most cases, semantic non-correspondence is such a situation, where the referential meaning of the word in the source language is consistent with that in the target language, but the implied meaning is different. “青” and “blue”, “细 淢” and “fine”, “清闲” and “quiet” serve as good examples to illustrate such cases.

(2) ST: 一层雨过, 云渐渐地卷向了西去, 天又青了, 太阳又露出脸来了...(ibid, p. 159)

TT: Soon when the rain is over, the clouds begin gradually to roll towards the west and the sun comes out in the blue sky" (ibid, p. 163).

“青” is used to talk about the state of the sky after rain. In terms of its implication, the color word highlights the bright and clean sky without dark clouds after rain which brings refreshing feeling to readers. However, the fact is that the color of the sky does not turn cyan after rain has given it a wash. Taking the context into consideration, the translator correctly understands the meaning of "青" (Its literal meaning is "green") and uses the word "blue" to depict the sky to show its clear and blue state after rain. "Blue" means having the colour of a clear sky or the sea on a clear day, which shows that the sky is not pallid. Therefore, “青”(green) is translated into "blue” according to the context of the ST. It is a case of semantic non-correspondence in translation.

(3) ST: 灰土上留下来的一条条扫帚的丝纹, 看起来既觉得细淢, 又觉得清闲...(ibid, p. 159)

TT: ...you will discover countless lines left by his broom in the dust, which look so fine and quiet...(ibid, p. 163)

“细㖑” and “清闲” describe the scene of broom marks on the dust in the source text, and also convey the author's perception. The translator did not equate the word “细㖑” with sensitive. With the same referential meaning, the two 
words here have different connotations. “细淢” refers to very delicate broom traces. Obviously, the word sensitive does not fit the context and fails to accurately convey the author's feelings about the scene. The word "fine" has the following interpretation in dictionary: "attractive and small or thin", "very thin or narrow", "used to say you are satisfied with something". The use of it by the translator not only shows the objective description and attraction of broom marks, but also expresses the author's comfort in that scene.

The corresponding results of the referential meaning of “清闲” in A New Century Chinese-English Dictionary (Hui $\mathrm{Yu}, 2004)$ is at leisure and idle, but the translator uses “quiet”. The word “清闲” is not to express the state of leisure, but to highlight the quiet environment. The word "Quiet" not only represents the environment without much noise, but also reflects that the author enjoys autumn without being interrupted. The choice of words in the translated text reproduces the tranquil picture formed by the interaction between people and environment in the source text.

\section{Semantic Zero}

"The absence of meaning of words is the result of the absence of cultural phenomena" (Chen Hongwei and Li Yazhou 2010, p. 35). There are differences between Chinese culture and English culture. Those Chinese words representing the unique Chinese culture might have no corresponding words in English, thus forming the phenomenon of zero referential meaning and zero implicative meaning. Some examples are given in the following.

(4) ST: 不过在中国，文字里有一个“秋士”的成语，读本里又有着很普通的欧阳子的秋声与苏东坡的《赤壁赋》 等...(ibid, p. 160)

TT: However, judging from the Chinese idiom qiushi (autumn scholar, meaning an aged scholar grieving over frustrations in his life) and the frequent selection in textbooks of Ouyang Xiu's On the Autumn Sough and Su Dongpo's On the Red Cliff... (ibid, p. 164)

In example (4), there are some typical expressions which are Chinese culture-related, which suggests that it is difficult for a translator to find their exact equivalents in English. Such expressions are “秋士”, “欧阳子” and “苏东坡”. “秋士” is an ancient Chinese term, literally meaning "autumn scholar". If it is translated as "autumn scholar”, the readers will feel puzzled about its meaning in the context. To convey its meaning in a clear way, the translator employed both approaches of transliteration and annotation. He used "qiushi" (a romanised alphabet called Chinese pinyin) to translate the term “秋士”, thus keeping its Chinese characteristic, and he explained its connotation by giving an annotation (autumn scholar, meaning an aged scholar grieving over frustrations in his life). In this way, the translator not only retains the characteristics of the Chinese language, but also introduces the cultural connotation of the word to the reader by adding in-text annotations. “欧阳子” and “苏东坡” are two well-known figures who enjoy great popularity in the circle of Chinese literature. They lived in the Northern Song Dynasty of China (960-1127AD). Transliteration of Chinese pinyin is employed in this case, so "Ouyang Xiu" and "Su Dongpo" appear in the TT as shown in the example. There is no doubt that such translation reflects the translator's respect for the Chinese language and culture, and at the same time it may add something new to the target language.

(5) ST: 比起北国的秋来, 正像是黄酒之与白干, 稀饭之与馍馍, 鲇鱼之与大蟹, 黄犬之与骆驼。(ibid, p. 161)

TT: Southern autumn is to Northern autumn what yellow rice wine is to kaoliang wine, congee to steamed buns, perches to crabs, yellow dogs to camels. (ibid, p. 165)

“黄酒”, “白干” and “馍馍”, three words with Chinese characteristics, are all translated in a free way, which effectively conveyed the cultural connotation to the readers. “黄酒” is a specialty of the Han nationality in China. It is made from glutinous rice and its color is mostly yellow. The translator translated it into "yellow rice wine", which not only presents the appearance of the wine, but also points out the source of the raw materials of the wine and highlights the uniqueness of the wine. “白干” refers to Hengshui Laobaigan Liquor, which is made from high-quality sorghum as raw material, pure wheat koji as starter culture and fermented in the ground jar. The translator accurately understands the reference object of “白干” and translated it into Kaoliang wine, which is convenient for readers to form a memory of this Chinese word and have a preliminary understanding of the production principle of this wine. “馍馍” is another name for “馒头”, a type of food made from fermented flour. Its translation "steamed buns" vividly reproduces the image of “馍馍” and helps readers to have a visual association with Chinese food. When the translator deals with the translation of these three words, he does not simply translate literally, but cleverly transliterates them in combination with the Chinese cultural context and the acceptance of readers.

\section{B. Syntactical Equivalence}

"Syntax is the study of the rules governing the ways different constituents are combined to form sentences in a language, or the study of the interrelationships between elements in sentence structures" (Hu Zhuanglin, 2011, p. 73). "The syntactic function shows the relationship between a linguistic form and other parts of the linguistic pattern in which it is used" (ibid, p. 81). Function names typically are subject, predicate, object, modifier, complement, etc.

The differences between Chinese and English sentences are mainly reflected in subject and predicate. Chinese, with syntactic feature topic-prominence and parataxis (which emphasizes the hidden logical association and meaning association), has flexible grammatical construction. Different types of words, which are often implicit, can be used as subjects of Chinese. Sentences with no subject appear in Chinese frequently. Chinese predicate components are 
complex, not dominated by subject, without personal, tense, number changes.

On the contrary, English, a subject prominent language, characterized by hypotaxis, which emphasizes the formal cohesion of the relationship between sentence elements, such as the singular and plural of English nouns, the tense and voice of predicate verbs, the relative pronouns connecting main clause and subordinate clause, and the conjunctions of compound sentences, have strict grammar requirements. English subjects are prominent and easy to be recognized. Only a noun or nominal phrase can be used as subjects. English predicate is absolutely subject to the subject, and its person, number must be consistent with those of the subject. It has the change of person, tense, number and voice.

Subject and predicate are not only syntactic functions, but also internal structural features of sentences. In addition to the variations in sentence internal structure, differences in Chinese and English syntax are expressed in terms of sentential connection. Most Chinese sentences have no explicit logical connectives and the sentences are loose. However, most English sentences are connected by explicit logical connectives and the sentences are complete and tight. The following three aspects of syntactic equivalence will be discussed in terms of the determination of subject, the choice of predicate and cohesion and coherence in sentence groups:

\section{Topic-Prominence Vs Subject-Prominence}

In the process of translating, the translator determines the subject of the target text mainly by means of three methods: taking the subject of the original text as the subject of the target text; Adding subject in the target text; Redefine the subject in translation. For instance,“北国的槐树, 也是一种能使人联想起秋来的点缀” (Zhang Peiji, 2007, p. 159)

(Locust trees in the North, as a decorative embellishment of nature, also associate us with autumn (ibid, p. 163). The translator adopted the subject "槐树" in the original text as the subject "Locust trees" in the translation. The last two methods of subject determination are illustrated with examples below:

（6） ST: (1)一个人夹在苏州上海杭州, (2)或厦门香港广州的市民中间, (3)浑浑沌沌地过去, (4)只能感到一点 点清凉, (5)秋的味, (6)秋的色, (7)秋的意境与姿态, 8总看不饱, (9)尝不透, (10赏玩不到十足。(ibid, p. 158)

TT: While muddling along all by myself among the urban dwellers of Suzhou, Shanghai, Xiamen, Hong Kong or Guangzhou, I feel nothing but a little chill in the air, without ever relishing to my heart's content the flavour, colour, mood and style of the season. (ibid, p. 162)

The translator splits the original into two parts in translation. The first half of the original sentence, (1)(2)(3), describes the scene of the author's shuttle in the crowd in the south of the Yangtze River in autumn, and the second half covers the rest. The subject of (1) is “一个人”。 (4)(5)(6)(7)(9)(10 expresses the author's feelings about the autumn of the South. (3)(4)(8)(10 are sentences without subject. In the translation corresponding to (4), the translator added the subject "I", and removed the subject “一个人” of (1), taking "I" as the subject of the whole idea group. This approach cleverly connects all the actions and movements of the author in the original text, namely, “夹”, “过去”, “感到”, “看”, “尝” and “赏玩”, which combines objective scene description and subjective emotion into one long sentence.

(7) ST: (1)这秋蝉的嘶叫, (2)在北平可和蟋蜶耗子一样, (3)简直像是家家户户都养在家里的家虫。(ibid, p. 159)

TT: Because of their ubiquitous shrill noise, these insects in Peiping seem to be living off every household like crickets or mice. (ibid, p. 163)

There are two subjects in the original text, one is the “秋蝉的嘶叫”, the other is the hidden subject “秋蝉” of (3). During the course of translating, the subject of the target text is "these insects", and “秋蝉的嘶叫” is treated as a prepositional phrase with a causal relationship. By the redetermination of the subject, the translation avoids the repeated appearance of “秋蝉” in the sentence, which accords with the conciseness requirement of English.

\section{Determination of Predicate}

It is seldom that the predicate in Chinese is used as the predicate in English in translation. In most cases, the translator not only needs to consider English grammatical norms, collocation habits and logical relations, but also needs to judge whether the translation can convey the textual meaning and semantic relevance of the source text, so as to re-choose the appropriate predicate.

(8) ST: (1)我的不远千里, (2)要从杭州赶上青岛, (3)更要从青岛赶上北平来的理由, (4)也不过想饱尝一尝这“秋”, (5)这故都的秋味。(ibid, p. 158)

TT: To enjoy its atmosphere to the full in the onetime capital, I have, therefore, made light of travelling a long distance from Hangzhou to Qingdao, and thence to Peiping. (ibid, p. 162)

The predicate in the source text is counted to two, which is “赶上” of (2) and (3) and “饱尝” of (4). The translator considered that the source text is located in the first paragraph of Autumn in Peiping, which highlights the author's yearning for autumn. Hence, the translator does not take these two verbs as the predicate of his translation, but uses Noun-Verb Shift rhetorical device, turning the noun phrase (1) into "made light of" as the predicate of his translation, which emphasized “我的不远千里". "Made light of" has an active relation with the subject "I" in the translation, "made", thus, does not use the passive voice. Because the original text is an event that happened in the past time, the predicate of the translation uses "made" (made is the past tense of make). The translator replaced the verb “赶上” with the preposition "to", which reflects the static characteristics of English. “饱尝” is treated as a non-predicate verb “To 
enjoy". Although its existence is not as strong as that of the predicate verb, the translator moves its position to the beginning of the translated sentence, which highlights the author's purpose of making such a long journey, which is to enjoy autumn.

\section{Cohesion and Coherence}

When processing sentential connection, the translator finds out the literal or potential semantic relations and logical relations of the source text, such as parallel relationship, continuity, progression, selection, causation, transition, condition, hypothesis, etc. Then, lexical repetition, ellipsis, conjunction, lexical collocation, reference, substitution and other cohesion means are used to achieve the discoursal cohesiveness.

(9) ST: ... (1)秋天, (2)这北国的秋天, (3)若留得往的话... (ibid, p. 161)

TT: Autumn, I mean Northern autumn, if only it could be made to last forever! (ibid, p. 165)

The translator adopts the reference method and uses the pronoun "it" to refer to "Northern autumn", which effectively avoids the occurrence of autumn several times in the translation and reflects the continuation relationship between clause (2) and clause (3). Conjunction method is also adopted by the translator, joining clauses (1) (2) and (3) with the conjunction "if". "If only" not only accurately translates "if", but also forms a hypotactic relationship between clauses (1) (2) and (3) in the translated text, thus demonstrating the hypothetical logic relationship of the whole long sentence.

\section{Stylistic Equivalence}

Prose is characterized by specific topic, a wide range of themes, flexible structure and varied techniques. Specifically speaking, it is realistic, lyric, arbitrary and epochal (Fu Demin, 1988, p. 12). Realism means that "it is the literary genre closest to the real life" (ibid, p. 12). It describes life by means of cutting, choosing, symbolizing and metaphor. Prose lyricism is more intense and direct than that of fiction, drama and other literary forms. The arbitrariness of prose is manifested in a wide-ranging of subjects, flexible forms and rich associations. "The epochal nature of prose is reflected in its rapid reflection of realistic struggles" (ibid, p. 19). Lyric prose is a narrative of people and events or one's experience, or paints the scene and object, expresses the feeling directly. Prose style is characterized by powerful expression function and aesthetic function. Whether these two functions are exploited is an important criterion to measure stylistic equivalence.

\section{Expressive Function}

Autumn in Peiping contains the author's lonely and melancholy state of mind, and the traces of his struggle between negative and positive emotions, and the deep love for autumn and motherland. The translator has a deep understanding of the author's feelings and has resonance with them. The translator's feelings were expressed in the words, so that autumn in the translation is "limpid, serene and melancholy" with author's emotions. 159)

(10) ST: 这秋蝉的嘶叫, 在北平可和蟋蟀耗子一样, 简直像是家家户户都养在家里的家虫。(张培基, 2007, p.

TT: Because of their ubiquitous shrill noise, these insects in Peiping seem to be living off every household like crickets or mice. (ibid, p. 163)

The translator adds two adjectives, ubiquitous and shrill. Ubiquitous means seeming to be everywhere or in several places at the same time. Shrill refers to sounds or voices very high and loud. The addition of two adjectives not only points out the reason why the author compares autumn cicadas to house insects, but also shows Yu Dafu's deep feeling of cicada sound.

(11) ST: 秋天, 这北国的秋天, 若留得往的话, 我愿把寿命的三分之二折去, 换得一个三分之一的零头。(张 培基, 2007, p. 161)

TT: Autumn, I mean Northern autumn, if only it could be made to last forever! I would be more than willing to keep but one-third of my life-span and have two-thirds of it bartered for the prolonged stay of the season! (ibid, p. 165)

In order to express his love for and attachment to Northern Autumn, the author adopts an exaggerated method, hoping to exchange the duration of Northern autumn in the four seasons with the length of his life. In the last paragraph of Autumn in Peiping, the translator uses two exclamatory sentences and the subjunctive mood to show the author's strong feelings.

\section{Aesthetic Appealing}

Yu Daizong (2006) believes that the aesthetic taste of Autumn in Peiping lies in two things. One is the clever use of "autumn" in the geographical space. Yu Dafu describes the northern autumn with the mentality of living in the South. Large-span spatial contrast makes the author's perception of northern autumn more vivid (ibid, p. 26). The other is the way to show aesthetic taste. The first step in choosing between southern autumn and northern autumn is to take an aesthetic stand. The second step is to perceive the aesthetic feeling of northern autumn from the perspective of the ordinary literati (ibid, p. 27). Liu Shicong ( 2002, p. 2-4) believes that the sound and rhythm of prose language, the artistic conception and atmosphere of the work, and the author's personalized way of discourse are three indispensable factors that enable the prose translation to reproduce the aesthetic value of the original text. These three essential factors are used to evaluate aesthetic appealing. 
However, it is rather difficult to reproduce the sound effect of the source text when translating from Chinese to English because Chinese is a tone language and English is an intonation language. The translator reproduces the rhythmic beauty of the source text when dealing with the translation of Autumn in Peiping. The source text reads smoothly and fluently, combining long and short sentences. Extra-long sentences are made up of short clauses, eliminating the weight of long sentences themselves. For example, “一层雨过，云渐渐地卷向了西去，天又青了，太 阳又露出脸来了; 著着很厚的青布单衣或夹袄的都市闲人，咬着烟管，在雨后的斜桥影里，上桥头树底下去一 立, 遇见熟人，便会用了缓慢悠闲的声调，微叹着互答着说” (Zhang Peiji, 2007, p. 59). Long sentences are interspersed with short ones such as subordinative compound in the target text, which unfolds the rhythmic beauty of the original text.

Language of source text is simple and plain, with characteristics of northern China. For instance, “一层秋雨一层凉 了” (ibid, p. 159). The pronunciation of “阵” in the North is similar to “层”. The words used in the target text have a similar style, almost common words, and the language is precise and simple, showing the sense of life in the source text.

Artistic conception in Chinese is “意境”. “境” in the source text refers to the vivid description of locust trees, cicadas, rain and fruit trees in Beijing. There are lonely locust trees, weak cicadas sound, appealing rain, fruit trees of golden days. “境” is the author's praise of autumn, melancholy and loneliness. The translation gives full play to the expression function of the source language and presents the sense of beauty of picture blended with scenes and emotions.

\section{CONCLUSION}

Under the guidance of functional equivalence theory, the translation analysis of Autumn in Peiping is made in three aspects: lexical equivalence, syntactic equivalence and stylistic equivalence. It is found that the theory of Functional equivalence has guiding effect on the translation of Autumn in Peiping and Chinese modern lyric prose.

In the analysis of lexical equivalence, the author finds that literal translation and free translation are often used in the translation process of semantic correspondence and semantic non-correspondence. Literal translation deals with words that only have referential meaning and are often associated with physical geography. Although some Chinese words can be equivalent in English, due to the influence of text context and writing background, it is suggested that the translation of them adopt the free translation method, and the translator needs to choose the most appropriate one in the target language under the premise of respecting the author's writing intention. Methods of free translation, transliteration and annotation are used for semantic zero. Transliteration associates the translation to retain the linguistic features of Chinese prose. As an auxiliary tool of transliteration, the annotation method optimizes the translation effect. Due to the differences in grammatical application between Chinese and English, the translator does not deal with syntactic equivalence translation mechanically in accordance with the Chinese sequence logic, but excavates the potential logic of Chinese and adjusts the translated sentence in terms of subject, predicate and sentential structure, so as to enable the translated text easier to be accepted by native English readers. Although the target text gives full play to the expression function and aesthetic value of the source text to a certain extent, it is still difficult to achieve stylistic equivalence completely, because part of the expression function and aesthetic value are tied together with the Chinese culture. However, The functional equivalence theory, which was grounded on the Bible translation, has certain limitations in the translation study of Chinese prose. Translators and readers may have different understandings of the source text, so it is inevitable that the translation analysis of Autumn in Peiping is subjective and may lead to individual differences in research results. Autumn in Peiping is just one of many works of Chinese modern lyric prose. It is not reasonable that the conclusion drawn from the analysis of a single work can be applied to all the translation studies of similar works. Future research on the translation of modern lyric prose in China may focus on the similarities and differences in translation techniques among several works, or the feasibility of improving the readability of translated works of this kind of prose.

\section{ACKNOWLEDGMENTS}

My great indebtedness goes to Professor Wang Wenjie for her extraordinary support in my paper writing. It is her encouragement and insight that help me greatly in my drafting. I also would like to extend my thanks to my teachers and classmates for their wonderful collaboration. In addition, my gratitude will go to my beloved parents and friends who have backed me up all the way.

\section{REFERENCES}

[1] An Interview with Dr. Eugene Nida. (1998). Foreign Languages (Journal of Shanghai International Studies University). (02): $2-6$.

[2] Bassnett-Mcguire, S. (1980). Translation Studies. London and New York: Routledge.

[3] Chen, H. W., \& Li Yazhou. (2010). A New Coursebook on Chinese-English Translation (Second Edition). Shanghai: Shanghai Foreign Lagrange Education Press.

[4] Fu, D. M. (1988). Prose Art. Chongqing: Chongqing Publishing House. 
[5] Guo J. Z. (1999). Contemporary American Translation Theory. Wuhan: Hubei Education Press.

[6] Hu, Z. L. (2011). Linguistics Course. Beijing: Peking University Press.

[7] Li J.J. (2013). Aesthetic Representation in English Translation of Modern Lyric Prose from the Perspective of Translation Aesthetics. Master Thesis. Northeastern University.

[8] Liu S. C. (2002). Chinese-English.English-Chinese Aesthetic Translation and Appreciation. Nanjing: Yilin Publishing House.

[9] Lu G. Q. (1999). Modern English Lexicology (New Edition). Shanghai: Shanghai Foreign Language Education Press.

[10] Lv G. (2010). Evidence and Reflection on the Model of Translation Quality Assessmentin Systemic Functional Linguistics. Foreign Language Studies, (02): 64-69+112.

[11] Nida, A. E., \& Jan De Waard. (1986). From One Language to Another: Functional Equivalence in Bible Translating. Nashville: Thomas Nelson.

[12] Nida, A. E. (2004). Toward a Science of Translating. Shanghai Foreign Lagrange Education Press.

[13] Ni W. H, \& Yang Yin. (2004). The Practicability of Nida's "Functional Equivalence" Theory from the Perspective of the Cultural Essence of Translation. Journal of Xi 'an International Studies University, (02): 34-36.

[14] Tan Z. X. (1999). A New Edition of Nida's Translation Theory. Beijing: China International Translation and Publishing Company.

[15] Tu G. Y., \& Liao Jing. (2001). A Review of the Concept of Translation Equivalence. Chinese Science and Technology Translation, (02): 40-43.

[16] Wang L. H., \& Shi Yanting. (2014). The Application of Functional Equivalence Theory in Literary Translation -- A Case Study of Translation Practice of Modern Saudi Arabian Literary Narrative Art. Foreign languages, 30(04): 123-126.

[17] Wilss, W. (1982). The Science of Translation: Problems and Methods. Tübingen: Gunter Narr.

[18] Yu D. \& Liu Shicong. (2014). On Rhythm in Prose Translation. Chinese Translation, 35(02): 92-96.

[19] Yu D. Z. (2006). On the Aesthetic Taste of Autumn in Beiping. Fujian Forum (Humanities and Social Sciences Edition), (02): 25-27.

[20] Zhang J. (2011). Retention, Loss and Change of Imagery in Chinese-English Translation of Idioms in Prose from the Perspective of Functional Equivalence -- A Case Study of Zhang Peiji's Selected Modern Chinese Prose in English Translation. Cultural and Educational Information, (11): 48-50.

[21] Zhang P. J. (2007). Selected Chinese Modern Prose in English Translation (I). Shanghai: Shanghai Foreign Language Education Press.

[22] Zhou L. S. (2015). Beauty and Truth in Prose Translation. Chinese Translation, 36(02): 117-119.

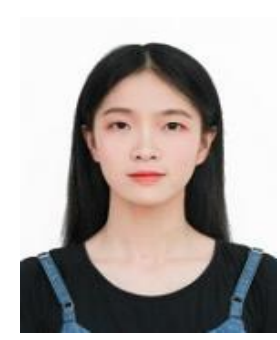

Rui Zhou was born in Baise, China, 1999. She earned a bachelor's degree in English language and literature from Guangxi University in June, 2021. She is currently studying for a master's degree at the College of Foreign Studies of Jinan University. Her research interests mainly include translation studies and language teaching. 